\title{
Environmental Monitoring and Evaluation of the X-Ray Field Flaw Inspection Workplace in a Factory Building
}

\author{
Qing $\mathrm{Li}^{1,2, *}$, Wei Xie ${ }^{3, *}$, Hong You ${ }^{2,4}$, Xiaohua Qiü, Quan Guo ${ }^{6}$, Lingxi Zhao ${ }^{1}$, Jing Zhang ${ }^{1}$, Wei Liu ${ }^{1}$ \\ ${ }^{1}$ Shandong Analysis and Test Center, Qilu University of Technology (Shandong Academy of Sciences), Jinan 250014, China \\ ${ }^{2}$ State Key Laboratory of Urban Water Resource and Environment, Harbin Institute of Technology, Harbin 150090, China. \\ ${ }^{3}$ School of Information science and Engineering, Harbin Institute of Technology at WeiHai, WeiHai 264209, China \\ ${ }^{4}$ School of Marine Science and Technology, Harbin Institute of Technology at Weihai, Weihai 264209, China \\ ${ }^{5}$ No. 1 institute of geology and mineral resources of Shandong Province, Jinan 250010, China \\ ${ }^{6}$ Qingdao Institute of Textile Fiber Supervision and Inspection, Qingdao 266000, China
}

\begin{abstract}
The surrounding radiation environment of the field flaw detection workplace has been theoretically calculated and monitored on site when an industrial X-ray flaw detector in a factory building is operated during the field flaw detection. The results show that when $5 \mathrm{~mA}$ tube current and $250 \mathrm{kV}$ tube voltage penetrate the steel tube at the thickness of $16 \mathrm{~mm}$ twice, the calculated value of the air kerma rate at the inspection point is basically consistent with the measured value. Additionally, the boundary of the controlled area and the supervised area corresponded to the measured value along the main beam direction belongs to the wall in the east of the workshop. The calculated distances of the leaking beam corresponding to the boundary of the controlled area and the supervised area of the calculated value should be $19 \mathrm{~m}$ and $58 \mathrm{~m}$, respectively. The minimum and maximum distances of the controlled area of the measured value are $13 \mathrm{~m}$ and $17 \mathrm{~m}$, respectively; while the maximum and minimum distances of the supervised area of the measured value are $31 \mathrm{~m}$ and $36 \mathrm{~m}$, respectively, both areas are within the workshop. Meanwhile, annual effective doses that might be accepted by professionals and the public have been estimated.
\end{abstract}

\section{INTRODUCTION}

The XXG-2505 industrial X-ray flaw detector is a ClassII ray device being ranked at the middle risk level, which may cause serious radiation damage to the persons exposed to radiation in an accident. What's worse, highdose radiation might even lead to death. Therefore, great importance must be attached to the protection and management of X-ray flaw detector. The project is to conduct on-site flaw detection in the factory building, which is performed in a fixed factory building. Therefore, the project also has the characteristics of flaw detection in the flaw detection room. On this basis, the division of the controlled area and the supervised area should be emphasized in the project among the main focuses of the influence exerted by the main beam, the leaking beam and its scattering.

Aiming at the practical situation of applying an industrial X-ray flaw detector in a factory building for field flawdetection, the suggestion of dividing the controlled area and the supervised is proposed in this paper based on theoretical calculation and monitoring verification of the radiation level in the workplace. Meanwhile, the likely acceptable annual effective doses of workers and the public are also estimated to comprehensively evaluate the radiation effect on the surrounding environment.

\section{Theoretical Calculation Measurement Methods}

\subsection{Basic situation of the workplace of field flaw detection}

The XXG-2505 X-ray flaw detector produced by Dandong Radiation Instrument Co., Ltd. is adopted in the X-ray field flaw inspection workplace within a factory building. Technical parameters of the device are shown in Table 1.

Table 1. Technical indicators of the industrial X-ray flaw detector.

\begin{tabular}{|c|c|}
\hline Model & XXG-2505 \\
\hline Input power & $220 \mathrm{~V} / 50 \mathrm{~Hz}, \mathrm{AC}$ \\
\hline Tube voltage & $150 \sim 250 \mathrm{Kv}$ \\
\hline Tube current & $5 \mathrm{~mA}$ \\
\hline
\end{tabular}




\begin{tabular}{|c|c|}
\hline Radiation form & Orientation \\
\hline X-ray radiation angle & $\pm 22.5^{\circ}$ \\
\hline Focus size & $2.0 \times 2.0 \mathrm{~mm}$ \\
\hline
\end{tabular}

To the east of the factory is the main road; to the east of the road is a gas station; to the north of the gas station is low-rise dwellings; to the north of the low-rise houses is a vegetable greenhouse; the north is a patrol service center of the police station; the west is farmlands; and the south is a wood-based company. The workplace for $\mathrm{X}$-ray field flaw inspection is confined to the wind tower welding workshop that is located in the northeast corner of the factory. It should be noted that the welding workshop was not designed and constructed as a special flaw inspection room. The general layout and the neighboring relationship of the factory are shown in Fig. 1 .

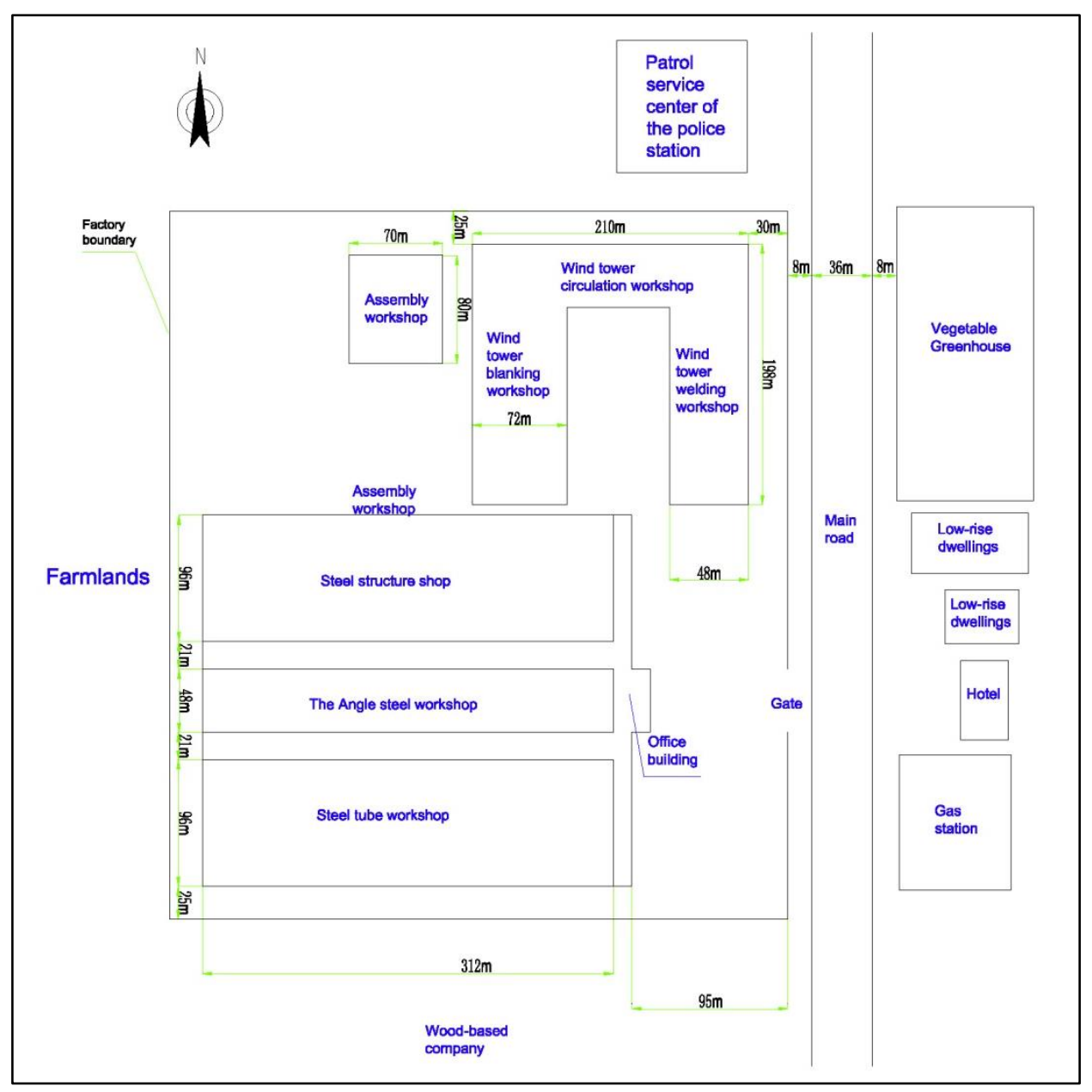

Fig. 1. The general layout and the neighboring relationship of the factory.

The wind tower workshop is composed of a wind tower blanking workshop, a wind tower circulation workshop and a wind tower welding workshop. There are 8 workers who engage in plate rolling and longitudinal seam welding in the day shift in the wind tower welding workshop. The wind tower circulation workshop mainly supplies materials and circulates semifinished products, which is operated by the remote control vehicle with nobody on duty. There are 20 workers who engage in girth welding in the day shift in the wind tower welding workshop.

The wind tower welding workshop is located at the northeast corner of the factory. The east of the workshop is an open space, $30 \mathrm{~m}$ away from factory boundary; the west is an open space, $70 \mathrm{~m}$ away from the wind tower blanking workshop; the south is a large open space where there is no worker; the north is an open space,
$25 \mathrm{~m}$ away from the factory boundary, which is connected to the north of the workshop and the wind tower circulation workshop. The location and the surrounding layout of the field flaw inspection workplace are shown in Fig. 2.

The wind tower workshop is $48 \mathrm{~m}$ in length from east to west and $198 \mathrm{~m}$ in length from north to south. Two 8meter-wide holes in the south are openings for objects (the qualified wind tower is delivered out of the workshop through the opening). Walls in the north and the south are concrete walls with $370 \mathrm{~mm}$ in thickness and $8 \mathrm{~m}$ in height in the lower part and color steel walls with $5 \mathrm{~mm}$ in thickness and $6 \mathrm{~m}$ in height in the upper part. Walls in the east and the west are concrete walls with $370 \mathrm{~mm}$ in thickness and $8 \mathrm{~m}$ in height in the lower part, color steel walls with $5 \mathrm{~mm}$ in thickness and $6 \mathrm{~m}$ in height in the upper part, and $5 \mathrm{~mm}$ color steel tiles on the roof. 
The location where the flaw detector is used in this project is about 80 meters away from the walls in the south and in the north, about 6 meters from the wall in the east; and about 42 meters from the wall in the west. Useful beams are adopted to have fixed irradiation on the wall in the east. The area irradiated with useful beams is a cone-shaped area at a coning angle of $45^{\circ}$. The use of the flaw detector, the useful beams irradiating area, and the monitoring (calculation) point setting are shown in Fig. 2 and Fig. 3.

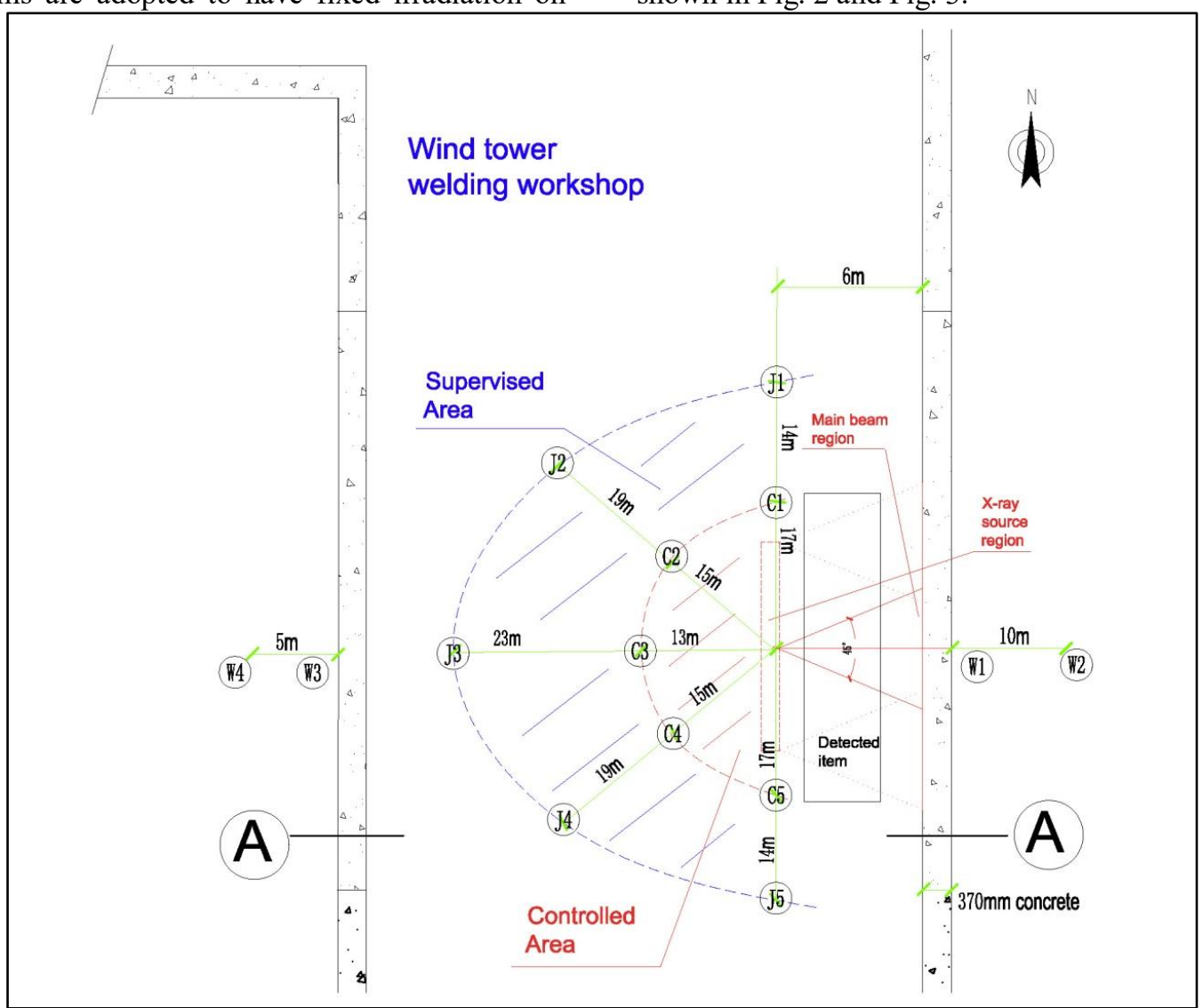

Fig. 2. Radiation monitoring spots-setting in the X-ray field flaw inspection workplace.

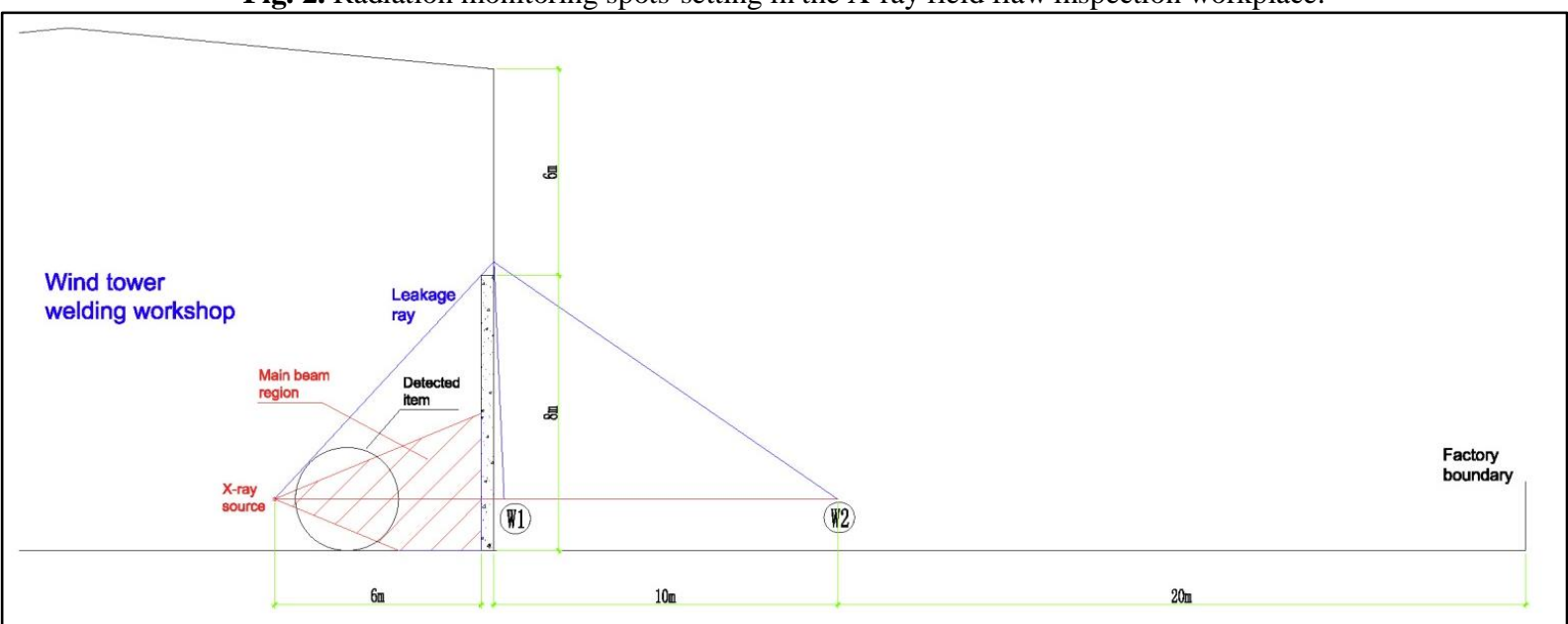

Fig. 3. The layout of the X-ray flaw detection room and radiation monitoring spots-setting in the workplace.

$\mathrm{kV}$ due to a variety of uncertainties in the actual

\subsection{Calculation methods}

The detected target in this project is the wind power tower steel tube with the wall thickness ranging from $10 \mathrm{~mm}$ to $30 \mathrm{~mm}$, the diameter ranging from $2.5 \mathrm{~m}$ to $4 \mathrm{~m}$ and the length ranging from $18 \mathrm{~m}$ to $28 \mathrm{~m}$. The thickness of the wind tower steel tube that should be detected by $\mathrm{X}$-ray is larger than or equal to $16 \mathrm{~mm}$. In the process of flaw detection, the tube voltage required for exposure curves of the flaw detector is between $150 \mathrm{kV}$ and 250 situations such as the type and the thickness of the components to be detected. Thus, estimating every situation is difficult.

For safety reasons, the steel tube at the thickness of $16 \mathrm{~mm}$ is taken as the detected target under the working condition that the tube voltage is $250 \mathrm{kV}$; the tube current is $5 \mathrm{~mA}$. By referring to the dividing base of the controlled area $\left(15 \mu \mathrm{Gy} \cdot \mathrm{h}^{-1}\right)$ [1] and the supervised area (greater than $1.5 \mu \mathrm{Gy} \cdot \mathrm{h}^{-1}$ ) [2], the calculation and the measurement of the X-ray dose rate in the workplace 
provide theoretical guidance for the actual radiation protection.

The air kerma rate of the main beam irradiating area [3] can be calculated as the Eq.1.

$$
\mathrm{D}=0.873 \times \mathrm{K}^{-1} \times \mathrm{X} / \mathrm{r}^{2}
$$

Where: $\mathrm{D}$ is the air kerma rate at the inspection point, $\mathrm{cGy} / \mathrm{h}$;

$\mathrm{X}$ is the $\mathrm{X}$-ray exposure rate at $1 \mathrm{~m}, \mathrm{R} / \mathrm{h}$;

0.873 is the conversion coefficient of exposure rate and dose rate, $\mathrm{cGy} / \mathrm{h} / \mathrm{R} / \mathrm{h}$;

$\mathrm{K}^{-1}$ is the attenuation coefficient of X-ray and materials, dimensionless;

$\mathrm{r}$ is the distance away from the X-ray machine, $\mathrm{m}$.

The exposure rate of the useful $\mathrm{X}$-ray beams produced by the X-ray machine at the distance of $\mathrm{r}$ from the focal spot of the X-ray tube can be approximately calculated by Eq. 2[4].

$$
X=I X_{0}\left(r_{0} / r\right)^{2}
$$

Where: $X$ is the exposure rate of the $\mathrm{X}$-ray machine at $r \mathrm{~m}, \mathrm{R} / \mathrm{min}$;

$I$ is the tube current, $\mathrm{mA}$;

$X_{0}$ is the output of the $\mathrm{X}$-ray machine at $\mathrm{r} 0 \mathrm{~m}$, $\mathrm{R} / \mathrm{mA} \cdot \mathrm{min}$;

$r$ is the distance away from the X-ray machine, $\mathrm{m}$.

The output and the exposure of the X-ray machine are related to the $\mathrm{X}$-tube type, voltage and voltage waveform, target material and shape, as well as material and thickness of the filter plate. The maximum tube voltage of the flaw detector in this project is $250 \mathrm{KV}$. According to the Volume I of the Radiation Protection Manual, the output $X_{0}$ of a typical X-ray machine with such a tube voltage ( $3.0 \mathrm{~mm}$ copper is the filter plate) at the distance of $1 \mathrm{~m}$ from the target is approximately 0.7 $\mathrm{R} / \mathrm{mA} \cdot \mathrm{min}$. The operating current of the flaw detector is considered in accordance with the maximum current of 5 $\mathrm{mA}$.

Radiation attenuation [5] of the $32 \mathrm{~mm}$ steel and the $370 \mathrm{~mm}$ concrete is calculated with TVT:

$$
K^{-1}=10^{-(h / T V T)} \text {. }
$$

Where: $K^{-1}$ is the attenuation coefficient of shielding radiation;

$h$ is the thickness of the shielding layer, mm;

$T V T$ is the thickness value of one tenth layer.

By referring to ICRP No.33 publication [6], when $250 \mathrm{kV}$ tube voltage and $32 \mathrm{~mm}$ steel are equivalent to $3.0 \mathrm{~mm}$ lead, and the shielding material is lead; the TVT of the X-ray of $250 \mathrm{kV}$ tube voltage is $2.9 \mathrm{~mm}$, the radiation attenuation $K^{-1}$ will be 0.092 . The TVT of $370 \mathrm{~mm}$ concrete is $9 \mathrm{~cm}$. The dose rate after the main beam passing through the concrete wall can be calculated as Eq. 4[5]:

$$
\mathrm{D}_{\mathrm{m}}=\mathrm{D}_{0} \times \mathrm{K}_{1}{ }^{-1} \times \mathrm{K}_{2}{ }^{-1} / \mathrm{r}^{2}
$$

Where: $\mathrm{D}_{0}$ is the air kerma rate of the main beam at $1 \mathrm{~m}\left(\mathrm{D}_{0}=0.873 X\right), \mathrm{cGy} / \mathrm{h}$.

The leaking beam will scatter after passing through the side wall of the color plate (above the concrete wall).
The scattering radiation is characterized by cosine distribution [5], which can be estimated by Eq. 5:

$$
\mathrm{D}_{\mathrm{l}}=\mathrm{D}_{0}{ }^{\prime} \times \mathrm{K}_{1}{ }^{-1} \operatorname{Cos} \theta / \mathrm{r}_{1}{ }^{2} \mathrm{r}_{2}^{2}
$$

Where: $\mathrm{D}_{0}$ ' is the air kerma rate of the leak beam at 1 $\mathrm{m}, \mathrm{cGy} / \mathrm{h}$;

$\mathrm{r}_{1}$-leaking distance, $\mathrm{m}$;

$\mathrm{r}_{2}$ - scattering distance, $\mathrm{m}$.

Hence, the air kerma rate $\mathrm{D}$ at the inspection point outside of the wall in the east is estimated with Eq. 6:

$$
\mathrm{D}=\mathrm{D}_{\mathrm{m}}+\mathrm{D}_{\mathrm{l}}
$$

\subsection{Monitoring instruments and methods}

The X-ray field flaw detection workplace is tested with the $451 \mathrm{P}$ pressurized ionization chamber survey meter produced by the INOVISION Company in America. The meter performance is shown in Table 2. The meter has

\begin{tabular}{|c|c|c|}
\hline No. & Project & Main parameters \\
\hline 1 & $\begin{array}{l}\text { Detecting } \\
\text { radiations }\end{array}$ & $\begin{array}{l}\beta \text {-ray that is greater } \\
\text { than } 1 \mathrm{MeV}, \gamma \text { and } \mathrm{X} \text { - } \\
\text { ray that are greater } \\
\text { than } 25 \mathrm{KeV}\end{array}$ \\
\hline 2 & Operating range & $\begin{array}{l}\text { There are } 5 \text { grades; } \\
\text { the lowest grade is } \\
\text { ranged from } 0 \text { to } \\
5 \mu \mathrm{Sv} / \mathrm{h} \text {; the highest } \\
\text { grade is ranged from } \\
0 \text { to } 50 \mathrm{mSv} / \mathrm{h} \text {. }\end{array}$ \\
\hline 3 & Accuracy & $\begin{array}{c}\text { The accuracy } \\
\text { between } 10 \% \text { and } \\
100 \% \text { of the full scale } \\
\text { indication at any } \\
\text { range should be } \\
\text { within } 10 \% \text {, except } \\
\text { for energy response. } \\
\text { The calibration } \\
\text { source is } 137 \mathrm{Cs} \text {. }\end{array}$ \\
\hline 4 & $\begin{array}{l}\text { Working } \\
\text { conditions }\end{array}$ & $-20^{\circ} \mathrm{C} \sim+50^{\circ} \mathrm{C}$ \\
\hline
\end{tabular}
been verified as qualified by the Shanghai Institute of Measurement and Testing Technology and is within the validity period.

Table 2. Main parameters of the 451P pressurized ionization chamber survey meter.

As stipulated in Requirements for Radio-logical Protection in Industrial X-ray Radiography (GBZ1172015) [1], monitoring points should be set in the workplace of X-ray field flaw detection. And the controlled area and the supervised area are divided through patrol.

\section{Results and Discussions}

\subsection{X-ray dose rate in the useful beams irradiating area}


When the flaw detection is conducted on a steel tube at the thickness of $16 \mathrm{~mm}$, the useful beam will pass through the tube at the thickness of $16 \mathrm{~mm}$ (or steel at $32 \mathrm{~mm}$ ) twice and pass through the concrete wall of

Table 3. X-ray dose rate at the useful beam direction of different distances with detection components (Tube voltage:250kV)

\begin{tabular}{|c|c|c|c|c|}
\hline \multirow{3}{*}{ Position } & \multicolumn{2}{|c|}{ Calculated value } & \multicolumn{2}{c|}{ Measured value } \\
\cline { 2 - 5 } & $\begin{array}{c}\text { 6m from the flaw } \\
\text { detector and } 30 \mathrm{~cm} \\
\text { behind the concrete } \\
\text { wall }\end{array}$ & $\begin{array}{c}10 \mathrm{~m} \text { from the flaw } \\
\text { detector and } 4 \mathrm{~m} \text { behind } \\
\text { the concrete wall }\end{array}$ & $\begin{array}{c}\text { 6m from the flaw } \\
\text { detector and } 30 \mathrm{~cm} \\
\text { behind the concrete } \\
\text { wall }(\mathrm{W} 1)\end{array}$ & $\begin{array}{c}10 \mathrm{~m} \text { from the flaw } \\
\text { detector and } 4 \mathrm{~m} \\
\text { behind the concrete } \\
\text { wall (W2) }\end{array}$ \\
\hline Dose rate & $0.39 \mu \mathrm{Gy} / \mathrm{h}$ & $0.29 \mu \mathrm{Gy} / \mathrm{h}$ & $0.44 \mu \mathrm{Gy} / \mathrm{h}$ & $0.27 \mu \mathrm{Gy} / \mathrm{h}$ \\
\hline
\end{tabular}

Note: The natural $\gamma$ radiation background is not deducted from test data in the table.

As can be seen from the above table, when the flaw detection is conducted on a steel tube at the thickness of $16 \mathrm{~mm}$, and the flaw detecting condition is the tube voltage of $250 \mathrm{kV}$ and the tube current of $5 \mathrm{~mA}$, the measured value of the calculation value of the X-ray dose rate in the useful beam direction are at the same radiation level. Moreover, the wall in the east of the workshop should be the boundaries of the controlled area and the monitoring area along the useful radiation direction.

The calculated value and the measured value of the $\mathrm{X}$-ray dose rate in the main beam radiating area are almost at the same radiation level, but not completely consistent. Main causes are as follows: 1. There are errors between the actual exposure rate and the
$370 \mathrm{~mm}$ to emit out of the workshop, as shown in Fig. 2 and Fig. 3. Calculation results and measured results are shown in Table 3.

Table 4. Calculated values of $X$-ray dose rates of leaking rays at different distances (Tube voltage:250kV).

\begin{tabular}{|c|c|c|c|c||c|c|}
\hline Distance & $1 \mathrm{~m}$ & $5 \mathrm{~m}$ & $10 \mathrm{~m}$ & $20 \mathrm{~m}$ & $\begin{array}{c}\text { Correspondin } \\
\mathrm{g} \text { distance of } \\
15 \mu \mathrm{Gy} / \mathrm{h}\end{array}$ & $\begin{array}{c}\text { Correspondin } \\
\mathrm{g} \text { distance of } \\
1.5 \mu \mathrm{Gy} / \mathrm{h}\end{array}$ \\
\hline Dose rate & $<5000 \mu \mathrm{Gy} / \mathrm{h}$ & $<200 \mu \mathrm{Gy} / \mathrm{h}$ & $<50 \mu \mathrm{Gy} / \mathrm{h}$ & $<12.5 \mu \mathrm{Gy} / \mathrm{h}$ & $18.3 \mathrm{~m}$ & $57.7 \mathrm{~m}$ \\
\hline
\end{tabular}

It can be seen from the above table that the distances of the controlled area and the monitoring area corresponding to the $250 \mathrm{KV}$ tube voltage in calculation should be $19 \mathrm{~m}$ and $58 \mathrm{~m}$, respectively.

The flaw detector is used for flaw detection in the wind tower welding workshop. A controlled area at the distance of $19 \mathrm{~m}$ can be divided in line with the length and width of the workshop (as shown in Fig.1 and Fig.2) at the tube voltage of $250 \mathrm{KV}$. Also, the north and the south of the supervised area can satisfy the requirement of $58 \mathrm{~m}$, while the width of the east and the west of the theoretical value; 2. Air decay in the X-ray is not considered [7] during calculation, resulting in the high calculated value; 3 . The density of the wall concrete is lower than that used for calculation, leading to the high calculated value.

\subsection{The dose rate of $X$-ray in the leaking ray radiating area}

When the tube voltage is greater than $200 \mathrm{KV}$, the air kerma rate of the leaking ray at $1 \mathrm{~m}$ is less than $5 \mathrm{mGy}^{-} \mathrm{h}^{-}$ ${ }^{1}[1]$. In this way, dose rates of leaking rays at different distances can be estimated, as shown in Table 4.

Table 5. Measured values of X-ray dose rates of leaking rays at different distances.

\begin{tabular}{|c|c|c|c|}
\hline No. & $\begin{array}{c}\text { Code of the } \\
\text { measuring point }\end{array}$ & Dose rate $(\boldsymbol{\mu G} / \mathbf{h})$ & Point of the measuring point \\
\hline 1 & C 1 & 15.1 & Form an angle of about $90^{\circ}$ with $17 \mathrm{~m}$ away from the flaw detector \\
\hline 2 & C2 & 15.1 & $\begin{array}{c}\text { Form an angle of about } 135^{\circ} \text { with the irradiating direction and } 15 \mathrm{~m} \\
\text { away from the flaw detector }\end{array}$ \\
\hline 3 & C3 & 15.2 & $\begin{array}{c}\text { Form an angle of about } 180^{\circ} \text { with the irradiating direction and } 13 \mathrm{~m} \\
\text { away from the flaw detector }\end{array}$ \\
\hline 4 & C4 & 15.2 & $\begin{array}{c}\text { Form an angle of about } 225^{\circ} \text { with the irradiating direction and } 15 \mathrm{~m} \\
\text { away from the flaw detector }\end{array}$ \\
\hline 5 & C5 & 15.1 & $\begin{array}{c}\text { Form an angle of about } 270^{\circ} \text { with the irradiating direction and } 17 \mathrm{~m} \\
\text { away from the flaw detector }\end{array}$ \\
\hline 6 & $\mathrm{~J} 1$ & 1.53 & $\begin{array}{c}\text { Form an angle of about } 90^{\circ} \text { with the irradiating direction and } 31 \mathrm{~m} \\
\text { away from the flaw detector }\end{array}$ \\
\hline
\end{tabular}




\begin{tabular}{|c|c|c|c|}
\hline 7 & J2 & 1.51 & $\begin{array}{c}\text { Form an angle of about } 135^{\circ} \text { with the irradiating direction and } 34 \mathrm{~m} \\
\text { away from the flaw detector }\end{array}$ \\
\hline 8 & $\mathrm{~J} 3$ & 1.52 & $\begin{array}{c}\text { Form an angle of about } 180^{\circ} \text { with the irradiating direction and } 36 \mathrm{~m} \\
\text { away from the flaw detector }\end{array}$ \\
\hline 9 & $\mathrm{~J} 4$ & 1.51 & $\begin{array}{c}\text { Form an angle of about } 225^{\circ} \text { with the irradiating direction and } 34 \mathrm{~m} \\
\text { away from the flaw detector }\end{array}$ \\
\hline 10 & $\mathrm{~J} 5$ & 1.52 & $\begin{array}{c}\text { Form an angle of about } 270^{\circ} \text { with the irradiating direction and } 31 \mathrm{~m} \\
\text { away from the flaw detector }\end{array}$ \\
\hline 11 & W3 & 0.22 & $\begin{array}{c}\text { Form an angle of about } 180^{\circ} \text { with the irradiating direction and } 30 \mathrm{~m} \\
\text { away from the concrete wall }\end{array}$ \\
\hline 12 & W4 & 0.16 & $\begin{array}{c}\text { Form an angle of about } 180^{\circ} \text { with the irradiating direction and } 5 \mathrm{~m} \\
\text { away from the concrete wall }\end{array}$ \\
\hline
\end{tabular}

Note: The natural $\gamma$ radiation background is not deducted from data in the table.

The controlled area and the supervised area can be divided in accordance with the measured values. The minimum and maximum distances of the controlled area of the measured value are $13 \mathrm{~m}$ and $17 \mathrm{~m}$, respectively; while the maximum and minimum distances of the supervised area of the measured value are $31 \mathrm{~m}$ and $36 \mathrm{~m}$, respectively, which are irregular sector areas, as shown in Fig.2. The controlled area and the supervised area of the measured value are within the workshop. The measured values are smaller than the theoretically calculated values. It's mainly because the actual value of the air kerma rate of the leaking ray is lower than the reference value provided by the standard. Also, air attenuation in the X-ray is not considered in the calculation [7]. What's more, the X-ray dose rate out of the wall in the west is basically consistent with the background level.

\subsection{Estimation of annual effective dose}

The X-ray flaw detector using in this project is operated discontinuously in the field with 2 workers who work for flaw inspection. The workload is as follows. Each piece is exposed for 3 minutes; 20 pieces are exposed daily. If it's worked 120 days annually, the annual exposure time will be about $3 \mathrm{~min} /$ piece $\times 20$ pieces $/ \mathrm{d} \times 120 \mathrm{~d} / \mathrm{a}=$ $120 \mathrm{~h} / \mathrm{a}$. If zoning is performed for 15 minutes daily and work for 72 days annually, the zoning working time will be $30 \mathrm{~h} / \mathrm{a}$. Occupancy factors are selected by referring to the revised ICRP No. 15 Publication [8], as shown in Table 6.

Table 6. Selection of occupancy factors.

\begin{tabular}{|c|c|}
\hline $\begin{array}{c}\text { Occupancy } \\
\text { factor }\end{array}$ & Occupancy position \\
\hline $\begin{array}{c}\text { Frequent } \\
\text { occupancy, } \mathrm{T}=1\end{array}$ & $\begin{array}{c}\text { Control room, office, waiting room, } \\
\text { operating room, dormitory, ward, and } \\
\text { children's playground }\end{array}$ \\
\hline $\begin{array}{c}\text { Partial } \\
\text { occupancy, } \mathrm{T}=1 / 4\end{array}$ & Utility room, and staff lounge \\
\hline $\begin{array}{c}\text { Temporary } \\
\text { occupancy, } \\
\mathrm{T}=1 / 16\end{array}$ & Toilet, stairs, escalator, parking lot, and \\
sidewalk
\end{tabular}

Personal dose can be estimated as Eq. 7[9].

$$
H=0.7 \times D r \times T \text {. }
$$

Where: $H$ is the equivalent of annual effective dose, $\mathrm{Sv} / \mathrm{a} \mathrm{Dr}$ is the air kerma rate, Gy/ h 0.7 is the conversion factor of absorbed dose to the equivalent of effective dose [9], Sv /Gy $T$ is the annual exposure time

\subsubsection{Annual effective doses of employees}

When field flaw detection is performed, one worker is responsible for operating the machine, while another worker is responsible for zoning. The worker who is responsible for operating the machine should stand at the leaking area, $25 \mathrm{~m}$ behind the machine, outside the controlled area and within the supervised area; while the zoning worker's range of activities is the area between the boundary of the controlled area and the boundary of the supervised area. For safety reasons, the X-ray dose rate of $15 \mu \mathrm{Sv} / \mathrm{h}$ in the boundary of the controlled area is taken as both workers' dose rates; $\mathrm{T}=1$ is taken as the occupancy factor; and the exposed time and the zoning time are $150 \mathrm{~h} / \mathrm{a}$. That is to say, the annual effective dose rate of a worker is $15 \mu \mathrm{Sv} / \mathrm{h} \times 150 \mathrm{~h} / \mathrm{a} \times 1 \times 0.7=1575 \mu \mathrm{Sv} / \mathrm{a}=1.58 \mathrm{mSv} / \mathrm{a} . \quad$ It $\quad$ is lower than the value constrained by the annual management dose (1/10 of the annual dose limit [10], [11]), $2 \mathrm{mSv} / \mathrm{a}$ used in this paper.

The title is set in bold 16-point Arial, justified. The first letter of the title should be capitalised with the rest in lower case. You should leave $35 \mathrm{~mm}$ of space above the title and $6 \mathrm{~mm}$ after the title.

\subsubsection{Annual effective doses of members of the public}

The public is not allowed to stay near the boundary of the supervised area frequently. Meanwhile, unrelated personnel should keep away from the workplace for flaw detection by taking measures such as cleaning the field, and setting up warnings, etc. For safety reasons, $T=1 / 4$ is taken as the occupancy factor; and the occupancy in the boundary of the supervised area is $150 \mathrm{~h} / \mathrm{a}$. As the X-ray dose rate in the boundary of the supervised area is $1.5 \mu \mathrm{Sv} / \mathrm{h}$, the annual effective dose rate of the public is $1.5 \mu \mathrm{Sv} / \mathrm{h} \times 150 \mathrm{~h} / \mathrm{a} \times 1 / 4 \times 0.7=39.375 \mu \mathrm{Sv} / \mathrm{a} \approx 0.04 \mathrm{mSv} / \mathrm{a}$, which is lower than the value constrained by the annual management dose, $0.3 \mathrm{mSv} / \mathrm{a}$ used in this paper[2].

\section{Conclusions and Suggestions}

It can be found that the calculated value of the air kerma rate at the inspection point is basically consistent with the measured value when $5 \mathrm{~mA}$ tube current and $250 \mathrm{kV}$ 
tube voltage penetrate the steel tube at the thickness of $16 \mathrm{~mm}$ twice upon calculation and measurement in the project. The boundary of the controlled area and the supervised area corresponded to the measured value along the main beam direction belongs to the wall in the east of the workshop. The calculated distances of the leaking beam corresponding to the boundary of the controlled area and the supervised area should be $19 \mathrm{~m}$ and $58 \mathrm{~m}$, respectively. Since the flaw detector is operated in a fixed workshop, a controlled area at the distance of $19 \mathrm{~m}$ can be divided in the workshop when the tube voltage is $250 \mathrm{KV}$. And the supervised area of $58 \mathrm{~m}$ can satisfy in the south and the north and cannot be satisfied in the east and the west due to the width limit in the workshop. Thus, the wall in the west of the workshop is defined as the boundary of the supervised area. The actual measurement shows that the minimum and maximum distances of the controlled area are $13 \mathrm{~m}$ and $17 \mathrm{~m}$, respectively; while the maximum and minimum distances of the supervised area are $31 \mathrm{~m}$ and $36 \mathrm{~m}$, respectively. All the areas are within the workshop. However, in practical work, the dose rate of X-ray around the workplace is also influenced by scattered rays, which is related to various factors such as the flaw detector, the object to be measured, the surrounding objects and the topography. The specific zoning management should be subject to the values measured by the field inspection device.

When the annual exposure time is $120 \mathrm{~h}$, the annual effective dose of a worker responsible for flaw detection and of the public are $1.58 \mathrm{mSv} / \mathrm{a}$ and $0.04 \mathrm{mSv} / \mathrm{a}$, respectively, satisfying the management requirement of "the annual management dose constraints of $2 \mathrm{mSv} / \mathrm{a}$ for workers who perform flaw detection and of $0.3 \mathrm{mSv} / \mathrm{a}$ for the public".

Furthermore, the construction unit must be equipped with protective equipment and radiation monitors such as warning signs, warning ropes, lead clothing, and personal alarm dosimeters, etc. All the objects that can be used for shielding and protection on site should be fully utilized during the field flaw detection. Steel plates equipped should be utilized as shielding materials. Workers should take full advantage of the cable length and operate in the controlled area. The cable length can be extended if necessary, so as to avoid that the cable is not long enough. Unrelated personnel should keep away from the workplace for flaw detection by taking measures such as cleaning the field, and setting up warnings, etc.

\section{Acknowledgments}

This study was jointly sponsored by the Key Research and Development Plan of Shandong Province (2018GGX101034), the National Natural Science Foundation of China (No.21703125), the Shandong Provincial Natural Science Foundation of China (ZR2016DQ17).

\section{References}

1. Institute of Radiation Medicine, Shandong Academy of Medical Sciences. GBZ117-2015 Requirements for Radio-logical Protection in Industrial X-ray Radiography [S]. Beijing: Standards Press of China, 1-7(2015).

2. China Institute of Atomic Energy. DB11/T 10332013 Requirements for Radiation Safety and Protection Classification Management of Industrial X-ray Flaw Detection [S]. Beijing Municipal Bureau of Quality and Technical Supervision, 1-10 (2013).

3. D F Zhang. Volume I of Ionizing Radiation Protection Technology and Management [M]. Nanning: Guangxi Nationalities Publishing House, 27-28(2003).

4. D P Li, Z Q Pan. Volume 1 Radiation Sources and Shielding of Radiation Protection Manual [M], Beijing: Atomic Energy Press, 233-237(1987).

5. S J Wang. Shielding Design and Evaluation of Radiation Source Storing Room [R]. National Continuing Education Project Information No. 2002-12-07-044, 6-26(2002).

6. ICRP. Protection against Ionizing Radiation from External Sources Used in Medicine ICRP Publication 33. [M]. Oxford: Pergamon Press, (1982).

7. S Zhu et al. Discussion on Industrial X Ray Flaw Detection Machine Radiation Protection Distance at the Operation Site Flaw Detection [J]. HUNAN NONFERROUS METALS, 31, 65-67(2015).

8. ICRP. Protection against Ionizing Radiation from External Sources ICRP 15 [M]. Oxford: Pergamon Press, (1970).

9. UNSCEAR. SOURCES AND EFFECTS OF IONIZING RADIATION-UNSCEAR 2000 Report to the General Assembly, with scientific annexes, Annex A: Dose assessment methodologies [M]. New York: UNITED NATIONS PUBLICATION, (2000).

10. Liaoning Instrument Research Institute. GB 224482008 Protection Rules for Industrial X-Ray Radiographic Equipment up to $500 \mathrm{kV}$ [S]. Beijing: Standards Press of China, 1-2(2008).

11. Nuclear Industry Standardization Institute. GB18871-2002 Basic Standards for Protection Against Ionizing Radiation and for the Safety of Radiation Sources [S]. Beijing: Standards Press of China, 35-36(2002). 